\title{
Peritonitis in Children: Experience in a Tertiary Hospital in Enugu, Nigeria
}

\author{
Chukwubuike Kevin Emeka ${ }^{a, *}$ \\ ${ }^{a}$ Department of Surgery, Enugu State University Teaching Hospital, Enugu, Nigeria.
}

\begin{abstract}
Background: Peritonitis may be associated with significant morbidity and mortality. The aim of this study was to evaluate our experience with the management of secondary peritonitis in children.

Methods: This was a retrospective study of children who had undergone laparotomy for peritonitis in the pediatric surgery unit of Enugu State University Teaching Hospital (ESUTH) in Enugu, Nigeria over a five-year period.

Results: There were 52 cases of laparotomies for peritonitis, with an age range of two weeks to 14 years (median: nine years) and a male to female ratio of 3.3:1. The etiologies of peritonitis were typhoid intestinal perforation in 25 cases $(48 \%)$, ruptured appendix in nine cases (17.3\%), perforated intussusception in eight cases (15.4\%), perforated external hernia in three cases (5.8\%), perforation due to adhesive intestinal obstruction in three cases (5.8\%), perforated necrotizing enterocolitis in three cases (5.8\%), and bowel perforation due to trauma in one case $(1.9 \%)$. The following definitive surgical procedures were performed: closure of bowel perforation in 26 cases (50\%), appendectomy plus abscess drainage in nine cases (17.3\%), right hemicolectomy with ileotransverse anastomosis in eight cases (15.4\%), segmental bowel resection in six cases (11.5\%), and insertion of peritoneal drains in three cases (5.8\%). The median duration of symptoms prior to presentation and the median duration from presentation to surgery were four days and two days, respectively. Twenty-four patients (46.2\%) developed complications that included surgical site infection in 12 cases (23.1\%), enterocutanous fistula in five cases $(9.6 \%)$, intra-abdominal abscess in four cases $(7.7 \%)$, and wound dehiscence in three cases (5.8\%). There were seven deaths, accounting for $13.5 \%$ of the patients.

Conclusion: Typhoid intestinal perforation was the most common cause of peritonitis in the present study.

Keywords: Children; peritonitis; developing country; single center
\end{abstract}

\section{INTRODUCTION}

Peritonitis can be defined as inflammation of the peritoneum regardless of its etiology, and it is a potentially life-threatening pathology ${ }^{[1]}$. Other terms synonymously used for peritonitis, but which are not exactly the same, include intra-abdominal infection or

\footnotetext{
* Corresponding author: Chukwubuike Kevin Emeka Mailing address: Department of Surgery, Enugu State University Teaching Hospital, Enugu, Nigeria.

E-mail: chukwubuikeonline@yahoo.com Received: 29 June 2020 / Accepted: 29 July 2020
}

intra-abdominal sepsis ${ }^{[1]}$. Peritonitis may be caused by perforation of the bowel or hollow viscus, as can occur with a ruptured appendix. Other causes of peritonitis include but are not limited to anastomotic leak and translocation of bacteria ${ }^{[1]}$. Peritonitis may be classified into primary, secondary, and tertiary peritonitis based on the source and nature of the microbial contamination ${ }^{[2]}$. Peritonitis may also be classified into localized or diffuse peritonitis.

In 1926, Kirschner demonstrated that by following strict surgical principles, the mortality rate of peritonitis could be reduced from $80 \%$ to about $60 \%{ }^{[3]}$. Subsequently, the development of new operative techniques, the provision of potent antibiotics, and the availability of intensive care treatment have reduced the mortality 
of peritonitis to an average of $30 \%$ to $40 \%{ }^{[4]}$. The factors that affect the outcome of peritonitis are related to the patient, the disease, and the intervention ${ }^{[5]}$. The goal of this study was to evaluate the profiles and management outcomes of children treated for secondary peritonitis at a tertiary hospital in Enugu, Nigeria.

\section{METHODS}

This was a retrospective study of children aged 15 years and below who were managed for peritonitis between January 2014 and December 2018 in the pediatric surgery unit of Enugu State University Teaching Hospital (ESUTH) in Enugu, Nigeria. Patients who had surgery for peritonitis at a peripheral hospital before referral to ESUTH for reoperation were excluded from the study, as were patients with primary peritonitis. ESUTH is a tertiary hospital located in Enugu, South East Nigeria. The hospital serves the entirety of Enugu State, which, according to the 2016 estimates of the National Population Commission and the Nigerian National Bureau of Statistics, has a population of about four million and a population density of $616.0 / \mathrm{km}^{2}$. The hospital also receives referrals from its neighboring states.

Information was extracted from the case notes, operation notes, operation register, and admission-discharge records. The information extracted included age, gender, presenting symptoms, duration of symptoms before presentation, time interval between presentation and intervention, intra-operative finding, definitive operative procedure performed, complications of treatment, duration of hospital stay, and outcome of treatment. The diagnoses of peritonitis were made based on clinical and radiological findings. The follow-up period was 12 months. Ethical approval was obtained from the ethics and research committee of ESUTH, and informed consent was obtained from the patients' caregivers. Statistical Package for Social Science (SPSS) version 21 (manufactured by IBM Corporation, Chicago, Illinois) was used for data entry and analysis. Data were expressed as percentages, medians, means, and ranges.

\section{RESULTS}

\section{Patients' demographics}

Sixty-two laparotomies were performed for peritonitis during the study period, but only 52 cases had complete case records; these formed the basis of this report. There were 40 males (76.9\%) and 12 females
(23.1\%), which corresponds to a male to female ratio of 3.3:1. Details are depicted in Table 1.

Table 1. Demographic characteristics of the patients $(n=52)$

\begin{tabular}{ll}
\hline Characteristics & \\
\hline $\begin{array}{l}\text { Gender } \\
\text { Male }\end{array}$ & $40(76.9 \%)$ \\
$\quad$ Female & $12(23.1 \%)$ \\
Age group of the patients & \\
$\quad$ Neonate (less than one month) & $3(5.8 \%)$ \\
$\quad$ Older than one month & $49(94.2 \%)$ \\
$\quad$ Median age of patients9 years & $(2$ weeks - 14 years) \\
Median duration of symptoms prior & 4 days (2-6) \\
to resentation & $7(13.5 \%)$ \\
$\quad \begin{array}{l}\text { Presented within } 24 \text { hours } \\
\text { Presented between } 24 \text { and } 48 \text { hours }\end{array}$ & $11(21.2 \%)$ \\
$\quad \begin{array}{l}\text { Presented after } 48 \text { hours } \\
\text { Median duration from presentation }\end{array}$ & $34(65.3 \%)$ \\
to surgery & 2 days $(1-3)$ \\
$\quad$ Within 24 hours & 7 patients $(13.5 \%)$ \\
$\quad$ Between 24 and 48 hours & 29 patients $(55.8 \%)$ \\
$\quad$ After 48 hours & 16 patients $(30.7 \%)$ \\
The mean duration of hospital stay & 12 days (7-21) \\
\hline
\end{tabular}

\section{Clinical features}

\section{Presenting symptoms}

Presenting symptoms are shown in Table 2.

Table 2. Presenting symptoms of the patients

\begin{tabular}{lcc}
\hline Presenting symptom & Number of patients & Percentage \\
\hline Abdominal pain & 28 & 53.8 \\
Fever & 10 & 19.2 \\
Abdominal distension & 6 & 11.6 \\
Vomiting & 5 & 9.6 \\
Constipation & 3 & 5.8 \\
\hline
\end{tabular}

\section{Clinical signs}

Fifty-two patients (96.2\%) had generalized abdominal tenderness, and 48 patients (92.3\%) had abdominal rigidity with guarding. On digital rectal examination, 26 patients $(50 \%)$ had collections in the rectovesical pouch.

\section{Radiological findings}

All the patients had plain abdominal radiographs; the radiographs were diagnostic in five patients $(9.6 \%)$. Forty-seven patients (90.4\%) had abdominal ultrasound, out of which 26 (55.3\%) showed echo-rich peritoneal fluid. Computed tomography scans were not performed as they were not available at the facility.

\section{Etiology of peritonitis}

Based on the intra-operative findings, the most common etiology causing peritonitis was typhoid intestinal perforation. Others are shown in Table3. 
Table 3. Etiology of peritonitis

\begin{tabular}{lcc}
\hline Intra-operative finding & Number of patients Percentage \\
\hline Typhoid intestinal perforation & 25 & 48.0 \\
Ruptured vermiform appendix & 9 & 17.3 \\
Perforated intussusception & 8 & 15.4 \\
Perforated external hernia & 3 & 5.8 \\
Perforated bowel due to AIO & 3 & 5.8 \\
Perforated NEC & 3 & 5.8 \\
Bowel perforation due to & 1 & 1.9 \\
abdominal trauma & & \\
${ }^{\mathrm{b}} \mathrm{NEC}=$ Necrotizing enterocolitis, ${ }^{\mathrm{a}} \mathrm{AIO}=$ Adhesive intestinal obstruc- \\
tion
\end{tabular}

\section{Definitive operation performed}

The definitive surgeries are shown in Table 4.

Table 4. Definitive operation

\begin{tabular}{lcc}
\hline Definitive procedure performed & $\begin{array}{c}\text { Number of } \\
\text { patients }\end{array}$ & Percentage \\
\hline Closure of bowel perforation & 26 & 50.0 \\
Appendectomy plus abscess drainage & 9 & 17.3 \\
Right hemicolectomy with ITA $^{c}$ & 8 & 15.4 \\
Segmental bowel resection & 6 & 11.5 \\
Peritoneal drain insertion & 3 & 5.8 \\
\hline
\end{tabular}

${ }^{\mathrm{c}} \mathrm{ITA}=$ Ileotransverse anastomosis

\section{Post-operative complications}

Twenty-eight patients (53.8\%) did not develop any complications. Surgical site infection occurred in 12 patients $(23.1 \%)$, and this was the most common complication recorded for the patients. Other complications included enterocutanous fistula in five cases (9.6\%), intra-abdominal abscess in four cases $(7.7 \%)$, and wound dehiscence in three cases (5.8\%).

\section{Outcome}

Forty-two patients (80.8\%) recovered well and were discharged. Two patients (3.8\%) were signed out against medical advice. Mortality was recorded in seven patients (13.5\%). Most mortality occurred among the neonates.

\section{Follow-up}

During the 12-month follow-up period, two patients (3.8\%) developed adhesive bowel obstruction. These two patients recovered upon non-operative treatment of their adhesive bowel obstruction.

\section{DISCUSSION}

Secondary peritonitis is a common emergency surgical condition managed by surgeons all over the world, and it represents a major cause of morbidity and mortality ${ }^{[6]}$. Secondary peritonitis results from the loss of integrity of the gastrointestinal tract, which leads to contamination of the peritoneal cavity by endogenous microflora ${ }^{[6]}$. Despite antimicrobial therapy, surgical intervention is the cornerstone of treatment for secondary peritonitis ${ }^{[7]}$.

In the present study, the male dominance of cases is consistent with the reports of other studies on secondary peritonitis ${ }^{[8,9,10]}$. However, Fowler reported a female dominance with regards to primary peritonitis ${ }^{[11]}$. The reason for this gender difference is not known. The median age of our patients of nine years is also similar to the reports of other studies ${ }^{[12,13]}$. The published median ages of patients with peritonitis vary from five to 11.8 years ${ }^{[10,14,15]}$. The median age of patients with peritonitis may be dependent on the predominant pathology in a particular setting. For instance, typhoid intestinal perforation occurs more in older children and intussusception is more common in infants. Further, for the patients in this study, there was a four-day median period before presentation to the hospital, and this finding is consistent with the reports of other studies ${ }^{[16,17,18]}$. This late presentation could be due to the poverty and ignorance that is prevalent in developing countries. Delays in investigating the patients and a paucity of funds may have accounted for the 48-hour lag period before surgery. The length of hospital stay of our patients was similar to that in the study conducted by Osifo et al. ${ }^{[10]}$. However, Obinwa reported a median hospitalization period of six days ${ }^{[12]}$. The length of hospital stay may be determined by the etiology of the peritonitis and the age of the patients. For instance, neonates who have peritonitis generally have longer hospital stays than older children ${ }^{[10]}$.

Abdominal pain, which was the predominant symptom in the present study, was also the most common symptom in other studies ${ }^{[9,17,18]}$. The symptoms of abdominal pain, fever, abdominal distension, vomiting, and constipation seen in our patients are similar to those reported by Nuhu et al. ${ }^{[17]}$. Typhoid intestinal perforation is one of the most dreaded and common complications of typhoid fever ${ }^{[19]}$. Typhoid intestinal perforation is observed in $0.8 \%$ to $39 \%$ of cases of typhoid fever ${ }^{[20]}$, and it is the most common cause of peritonitis, especially in developing countries ${ }^{[17]}$. The findings of the present study are consistent with this fact. However, other studies have reported that a ruptured appendix is the most common cause of secondary peritonitis in children ${ }^{[10,12]}$.

The definitive procedure performed on our patients was dependent on the etiology of the peritonitis. Ex- 
cision of the edge of the intestinal perforation and simple transverse closure in two layers was the most common procedure in our patients. A study conducted in Tanzania also adopted this method of treatment for typhoid intestinal perforation ${ }^{[21]}$. However, segmental ileal resection with primary end-to-end anastomosis for typhoid intestinal perforation is another option for treatment ${ }^{[22,23]}$. Laparotomy following peritonitis is froth with many post-operative complications. Surgical site infection, which we recorded as the most common complication, has also been consistently observed by other researchers ${ }^{[5,9,17]}$. Enterocutanous fistula is a potentially catastrophic post-operative complication and was recorded in about one tenth of our patients. This is similar to the findings reported by Nuhu et al. ${ }^{[17]}$. However, a study conducted in Benin, Nigeria reported no incidence of enterocutanous fistula following surgery for peritonitis ${ }^{[10]}$. Thus, the development of an enterocutanous fistula after laparotomy may depend on the primary pathology or modality of treatment.

The mortality rate of $13.5 \%$ in the present study is comparable to the rates reported by other researchers ${ }^{[5,9,18]}$. However, the published mortality rates of secondary peritonitis range from $8.8 \%$ to $26.1 \%{ }^{[5]}$. In the present study, the most common cause of mortality was overwhelming sepsis due to late presentation and complications arising from the surgery itself. The age of the patient, degree of peritoneal contamination, and duration of surgery are some factors that may affect mortality in children who have peritonitis ${ }^{[5]}$.

\section{Strength of the study}

Treatment of peritonitis in children that developed from a wide range of causes was discussed in this study. Data on pediatric peritonitis, unlike adult peritonitis, is not readily available, especially in developing countries.

\section{Weakness/limitations of the study}

This was a retrospective study; a prospective study would have provided more information for analysis. The generalizability of this study was also limited by the small number of cases that was considered. Further, this was a single institution experience that may not be generalizable to other institutions.

\section{CONCLUSION}

In the present study, the demographics, clinical features, radiological features, etiologies, surgical proce- dures performed, post-operative complications, and management outcomes of children with peritonitis were evaluated. Typhoid intestinal perforation was the most common etiology of peritonitis, and closure of bowel perforation was the most frequently performed surgical procedure. The current state of late presentation and poor outcome should be improved upon.

\section{DECLARATIONS}

\section{Authors' contribution}

The author contributed solely to this article.

\section{Availability of data and materials}

Data is available with the author and can be provided on request.

\section{Conflict of interest}

The author declares that there is no conflict of interest.

\section{Ethical approval}

Ethical approval was obtained from the hospital ethics committee.

\section{REFERENCES}

1. Tochie, J. N., Agbor, N. V., Frank, T. L., Mbonda, A., Aji, D. A., \& Danwang, C. (2020). Global epidemiology of acute generalised peritonitis: a protocol for a systematic review and meta-analysis. BMJ open, 10(1), e034326-e034326.

2. Ross, J. T., Matthay, M. A., \& Harris, H. W. (2018). Secondary peritonitis: principles of diagnosis and intervention. BMJ (Clinical Research ed.), 361, k1407-k1407.

3. Jaiswal, S., \& Sharma, S. C. (2020). Role of peritoneal drainage in moribund patients of perforation peritonitis. International Surgery Journal, 7(5), 1357-1360.

4. Holzheimer, R. G. (2001). Management of secondary peritonitis. In Surgical Treatment: Evidence-Based and Problem-Oriented. Zuckschwerdt.

5. Ayandipo, 0. O., Afuwape, 0. O., Irabor, D. O., Abdurrazzaaq, A. I., \& Nwafulume, N. A. (2016). Outcome of laparotomy for peritonitis in 302 consecutive patients in Ibadan, Nigeria. Annals of Ibadan postgraduate medicine, 14(1), 30-34.

6. Sartelli, M., Catena, F., Abu-Zidan, F. M., Ansaloni, L., Biffl, W. L., Boermeester, M. A., ... \& Di Saverio, S. (2017). Management of intra-abdominal infections: recommendations by the WSES 2016 consensus conference. World Journal of Emergency Surgery, 12(1), 1-31.

7. Van Ruler, O., \& Boermeester, M. A. (2016). Surgical treatment of secondary peritonitis: A continuing problem. German version. Der Chirurg; Zeitschrift fur alle Gebiete der operativen Medizen, 87(1), 13. 
8. Axler, J. P., Toussaint, S., \& Alouidor, J. (2020). Descriptive and correlational study of of peritonitis in the surgical department of the State University Hospital of Haïti (HUEH): A cross sectional study. International Journal of Surgery Open,24,105-111.

9. Mabewa, A., Seni, J., Chalya, P. L., Mshana, S. E., \& Gilyoma, J. M. (2015). Etiology, treatment outcome and prognostic factors among patients with secondary peritonitis at $\mathrm{Bu}$ gando Medical Centre, Mwanza, Tanzania. World Journal of Emergency Surgery, 10(1), 47.

10. Meena, L. N., Jain, S., \& Bajiya, P. (2017). Gastrointestinal perforation peritonitis in India: A study of 442 cases. Saudi Surgical Journal, 5(3), 116.

11. Khilji, M. F. (2015). Primary Peritonitis-A Forgotten Entity. European journal of pediatric surgery reports, 3(1), 27.

12. Obinwa, O., Casidy, M., \& Flynn, J. (2014). The microbiology of bacterial peritonitis due to appendicitis in children. Irish Journal of Medical Science (1971-), 183(4), 585-591.

13. Sethna, C. B., Bryant, K., Munshi, R., Warady, B. A., Richardson, T., Lawlor, J., ... \& Neu, A. (2016). Risk factors for and outcomes of catheter-associated peritonitis in children: the SCOPE collaborative. Clinical Journal of the American Society of Nephrology, 11(9), 1590-1596.

14. Chinchilla, J., Sebastián, K., Meléndez, R., Ramay, B., \& Lou-Meda, R. (2016). Risk Factors for Peritonitis in a Pediatric Dialysis Program in Guatemala, 2011-2014.

15. Sutherland, S. M., Alexander, S. R., Feneberg, R., Schaefer, F., Warady, B. A., \& International Pediatric Peritonitis Registry (IPPR). (2010). Enterococcal peritonitis in children receiving chronic peritoneal dialysis. Nephrology Dialysis Transplantation, 25(12), 4048-4054.

16. Doklestić, S. K., Bajec, D. D., Djukić, R. V., Bumbaširević,
V., Detanac, A. D., Detanac, S. D., ... \& Karamarković, R. A. (2014). Secondary peritonitis-evaluation of 204 cases and literature review. Journal of medicine and life, $7(2)$, 132-138.

17. Ali, N., \& Gali, B. M. (2010). Causes and treatment outcome of perforation peritonitis in north eastern Nigeria. Surgical practice, 14(3), 92-96.

18. Chichom-Mefire, A., Fon, T. A., \& Ngowe-Ngowe, M. (2016). Which cause of diffuse peritonitis is the deadliest in the tropics? A retrospective analysis of 305 cases from the South-West Region of Cameroon. World Journal of Emergency Surgery, 11(1), 14.

19. Sharma, A. K., Sharma, R. K., Sharma, S. K., Sharma, A., \& Soni, D. (2013). Typhoid intestinal perforation: 24 perforations in one patient. Annals of medical and health sciences research, 3(1a), 41-43.

20. Contini, S. (2017). Typhoid intestinal perforation in developing countries: Still unavoidable deaths?. World Journal of Gastroenterology, 23(11), 1925.

21. Chalya, P. L., Mabula, J. B., Koy, M., Kataraihya, J. B., Jaka, H., Mshana, S. E., ... \& Gilyoma, J. M. (2012). Typhoid intestinal perforations at a University teaching hospital in Northwestern Tanzania: A surgical experience of 104 cases in a resource-limited setting. World journal of emergency surgery, 7(1), 4.

22. Sheshe, A. A., Anyanwu, L. J. C., Mohammad, A. M., Muhammad, A. B., \& Obaro, S. K. (2018). Typhoid intestinal perforation: Analysis of the outcome of surgical treatment in Kano, Nigeria. Archives of Medicine and Health Sciences, 6(1), 59.

23. Patel, A., Kelly, P., \& Mulenga, M. (2019). Surgical management of typhoid ileum perforations: a systematic review. Medical Journal of Zambia, 46(4), 349-356. 